\title{
The Strong Cough: Is It a Signpost on the Road to Extubation or Just a Dead End?
}

In the field of medicine, success has been measured by patient survival. True victory, however, should be judged by the patient's liberation and independence from further medical intervention. This is particularly true in critical care medicine and the field's prototypical intervention: mechanical ventilation. Its role as a life-sustaining treatment in acute respiratory failure and other critical illnesses has been invaluable, but its potential for harm cannot be overstated. Both acute lung injury after the institution of mechanical ventilation and ventilator-associated pneumonia have been well described. ${ }^{1,2}$ Orally intubated patients are often bedridden, which can negatively facilitate physical deconditioning, sarcopenia, and poor functional status, especially if mechanical ventilation is prolonged. ${ }^{3,4}$ Timely and safe liberation from mechanical ventilation has, therefore, become a goal in the ICU.

The determination of ventilator liberation readiness has attempted to move from a gestalt based on physician experience to a protocolized multispecialty screening process. $^{5}$ The spontaneous breathing trial (SBT) is designed to test the patient's ability to endure the physiologic stress of maintaining appropriate gas exchange with minimal assistance from the ventilator. Simply undergoing this challenge, however, is not enough to guarantee a successful extubation. Extubation failure (ie, the need to be reintubated within the first 48-72 h) after an SBT occurs in $8.5 \%$ of surgical ICU patients and is as high as $25 \%$ in the medical ICU population. The consequences of a failed extubation can be dire, as they are associated with mortality rates as high as $43 \% .6,7$ The focus of research in ventilator liberation has been to identify patient characteristics and physiologic performance measures during an SBT that will predict with certainty patients who will remain ventilator-free after extubation. Multiple risk factors for extubation failures have been identified: encephalopathy, ICU-acquired muscle weakness, cardiac dysfunction, ongoing lung pathology, and upper airway obstruction. ${ }^{8}$

\footnotetext{
The authors have disclosed no conflicts of interest.
}

Correspondence: Ulrich H Schmidt MD PhD MBA, Department of Anesthesiology, University of California San Diego, 200 W. Arbor Drive, MC\# 8770, San Diego, CA 92103-8770. Email: uschmidt@ucsd.edu.

DOI: $10.4187 /$ respcare.05894
Single measures such as the rapid-shallow breathing index, duration of SBT, muscle strength, and $\mathrm{P}_{\mathrm{aCO}}$ have been used to test patients' endurance, power, and lung function. ${ }^{6,7,9}$ Brain natriuretic peptide levels and measurements of

See the Original Study on Page 1505

diastolic function by transthoracic echocardiography have been proposed to measure cardiac function, and a cuff-leak test for upper airway obstruction has been advocated in the most recent American Thoracic Society/American College of Chest Physicians practice guideline for assessing ventilator liberation readiness. ${ }^{7,10}$ These tests, by themselves, are moderately able to predict the success of a patient population, but they are less successful in predicting an individual's success, as evidenced by the relatively unchanged re-intubation rate. This suggests that there may be other conditions that need to be considered.

Extubation failure after a successful SBT has been linked to poor pulmonary hygiene. ${ }^{11}$ Secretion management has been subjectively assessed by the degree of secretion production. Coughing, or the ability to expel secretion and debris, has been demonstrated to be predictive of extubation success. ${ }^{8}$ Measurement of the ventilated patient's cough strength has ranged from qualitative assessments to the exotic white card spit test, where the patient's ability to spit and leave a mark on card is considered acceptable. ${ }^{12}$ In this issue of Respiratory CARE, Gobert et al ${ }^{13}$ studied the use of cough peak flow, an objective quantitative measurement of cough strength during SBT. What is novel about their approach is the use of a native built-in flow meter that is a feature of a commercially available ventilator to measure cough peak flow at the conclusion of a standardized SBT protocol. Their results are similar to previously published data utilizing external flow meters, ie, higher peak flows were seen in successfully extubated patients, but with the added benefit that any health care provider could collect the data by reviewing the ventilator screen read-out. ${ }^{14,15}$ Can a quantitative measure of cough strength predict successful extubation? From the data presented, the cough peak flow measured at the end of SBT had a high positive predictive value for early extubation success, yet its ability to discriminate between success and failure was poor with an area under curve value of 0.61 , 


\section{EDITORIALS}

lower than previously published values. ${ }^{14,15}$ When paired with tidal volumes nearing the end of SBT, the area under curve value improved slightly to 0.64 . The authors were able to improve the negative predictive value when the patient's end-SBT pH was included. The results of this study conveys two messages. First, it confirms that cough strength is an important consideration for extubation. The second is that the prediction of extubation success cannot rely on a single variable but requires identification of synergistic relationships between multiple variables.

The advancement in the science of respiratory care, this article included, has given the practitioner more tools to determine patient candidacy for ventilator liberation. These assessments, however, have limitations, and the decision to extubate is still based on a clinician's educated guess. Being able to predict extubation success with $100 \%$ accuracy remains an elusive goal. Should we perhaps be asking these questions: "Will this test tell me why my patient will fail extubation? What can done to optimize the patient?" Viewed in this manner, a low cough peak flow would lead the clinician to identify its cause such as malnutrition or physical deconditioning. Treatments such as nutrition optimization and pulmonary rehabilitation can remedy the situation. On the journey to extubation success, we should seek out the signposts that identify patients at risk for extubation failure and target therapies to improve their individual needs to arrive safely at their destination.

\section{Albert P Nguyen MD Ulrich H Schmidt MD PhD MBA \\ Department of Anesthesiology University of California San Diego San Diego, California}

\section{REFERENCES}

1. Gajic O, Dara S, Mendez J, Adesanya A, Festic E, Caples S, et al. Ventilator-associated lung injury in patients without acute lung injury at the onset of mechanical ventilation. Crit Care Med 2004; 32(9):1817-24.
2. Valencia M, Torres A. Ventilator-associated pneumonia. Curr Opinion Crit Care 2009;15(1):30-35.

3. De Jonghe B, Sharshar T, Lefaucheur J, Authier F, Durand-Zaleski I, Boussarsar M, et al. Paresis acquired in the intensive care unit: a prospective multicenter study. JAMA 2002;288(22):2859-67.

4. Bailey P, Thomsen GE, Spuhler VJ, Blair R, Jewkes J, Bezdjian L, et al. Early activity is feasible and safe in respiratory failure patients. Crit Care Med 2007;35(1):139-45.

5. Ely EW, Baker AM, Dunagan DP, Burke H, Smith A, Kelly P, et al. Effect on the duration of mechanical ventilation of identifying patients capable of breathing spontaneously. N Engl J Med 1996; 335(25):1864-69.

6. Piriyapatsom A, Williams EC, Waak K, Ladha KS, Eikermann M, Schmidt UH. Prospective observational study of predictors of reintubation following extubation in the surgical ICU. Respir Care 2016;61(3):306-15.

7. Jeganathan N, Kaplan CA, Balk RA. Ventilator liberation for highrisk-for-failure patients: improving value of the spontaneous breathing trial. Respir Care 2015;60(2):290-96.

8. Thille AW, Boissier F, Ben Ghezala H, Razazi K, Mekontso-Dessap A, Brun-Buisson C. Risk factors for and predictions by caregivers of extubation failure in the ICU patients: a prospective study. Crit Care Med 2015;43(3):613-20.

9. Yang KL, Tobin MJ. A prospective study of indexes predicting the outcome of trials of weaning from mechanical ventilation. N Engl J Med 1991;324:1445-50.

10. Girard TD, Alhazzani W, Kress JP, Ouellette DR, Schmidt GA, Truwit JD, et al. An official American Thoracic Society/American College of Chest Physicians clinical practice guideline: liberation from mechanical ventilation in critically ill adults. Rehabilitation protocols, ventilator liberation protocols, and cuff leak tests. Am J Respir Crit Care Med 2016;195(1):120-33.

11. Demling RH, Read T, Lind LJ, Flanagan HL. Incidence and morbidity of extubation failure in surgical intensive care patients. Crit Care Med 1988;16(6):573-77.

12. Salam A, Tilluckdharry L, Moateng-Adjepong Y, Manthous CA. Neurologic status, cough, secretions and extubation outcomes. Intensive Care Med 2004;30(7):1334-39.

13. Gobert F, Yonis H, Tapponnier R, Fernandez R, Labaune MA, Burle JF, et al. Predicing extubation outcome by cough peak flow measured using the built-in ventilator flow-meter. Respir Care 2017; 62(12):1505-19.

14. Duan J, Liu J, Xiao M, Yang X, Wu J, Zhou L. Voluntary is better than involuntary cough peak flow for predicting re-intubation after scheduled extubation in cooperative subjects. Respir Care 2014; 59(11):1643-51.

15. Su W-L, Chen Y-H, Chen C-W, Yang SH, Su CL, Perng WC, et al. Involuntary cough strength and extubation outcomes for patients in an ICU. Chest 2017;137(4):777-82. 